NBER WORKING PAPER SERIES

\title{
STOCHASTIC PROBLEMS IN THE SIMULATION \\ OF LABOR SUPPLY
}

Jerry A. Hausman

Working Paper No. 188

\author{
NATIONAL BUREAU OF ECONOMIC RESEARCH \\ 1050 Massachusetts Avenue \\ Cambridge MA 02138 \\ October 1981
}

This paper was presented at the NBER Conference on Behavioral Simulation Methods in Tax Policy Analysis, January 25-27, 1981, Palm Beach. Research support has been provided by HHS, NSF, and the NBER. Paul Ruud and Ken West have given excellent research assistance. The research reported here is part of the NBER's research programs in Taxation and Labor Studies and project in Tax Simulation. Any opinions expressed are those of the author and not those of the National Bureau of Economic Research. 
NBER CONFERENCE PAPER SERIES

Papers Available from the Conference on

SIMULATION METHODS IN TAX POLICY ANALYSIS

Palm Beach, Florida

Conference

January 25-27, 1981

Paper

No.

WP 497 "Alternative Tax Treatments of the Family: Simulation Methodology and Results," by Daniel Feenberg and Harvey S. Rosen

WP 788 "Stochastic Problems in the Simulation of Labor Supply," by Jerry Hausman

"Alternatives to the Current Maximum Tax on Earned Income," by Lawrence B. Lindsey

"The Distribution of Gains and Losses from Changes in the Tax

Treatment of Housing," by Mervyn King

WP 682 "Simulating Nonlinear Tax Rules and Nonstandard Behavior: An Application to the Tax Treatment of Charitable Contributions," by Martin Feldstein and Lawrence B. Lindsey

"Issues in the Taxation of Foreign Source Income," by Daniel Frisch

WP 583 "Modeling Alternative Solutions to the Long-Run Social Security Funding Problem," by Michael Boskin, Marcy Avrin, and Kenneth Cone

"Domestic Tax Policy and the Foreign Sector: The Importance of Alternative Foreign Sector Formulations to Results from a General Equilibrium Tax Analysis Model," by Lawrence Goulder, John Shoven, and John Whalley

WP 673 "A Reexamination of Tax Distortions in General Equilibrium Models," by Don Fullerton and Roger Gordon

"A General Equilibrium Model of Taxation with Endogenous Financial Behavior," by Joel Slemrod

WP 681 "Alternative Tax Rules and Personal Savings Incentives: Microeconomic Data and Behavioral Simulations," by Martin Feldstein and Daniel Feenberg

WP 729 "National Savings, Economic Welfare, and the Structure of Taxation," by Alan Auerbach and Laurence Kotlikoff

"Tax Reform and Corporate Investment: A Micro-Econometric Simulation Study," by Michael Salinger and Lawrence Summers

It is expected that the papers resulting from this conference will be published in a volume edited by Martin Feldstein.

Copies of these conference papers may be obtained by sending $\$ 1.50$ per copy to Conference Papers, NBER, 1050 Massachusetts Avenue, Cambridge, MA 02138. Please make checks payable to National Bureau of Economic Research. Advance payment is required on orders totaling less than $\$ 10.00$ 


\section{List of Participants \\ SIMULATION METHODS IN TAX POLICY ANALYSIS}

The Breakers, Palm Beach

January 25-27, 1981

$\underline{\text { Name }}$

Henry J. Aaron Alan J. Auerbach Martin J. Bailey Michael J. Bo skin Daniel R. Feenberg Martin Feldstein Daniel J. Frisch Don Fullerton Harvey Galper Roger H. Gordon Lawrence H. Goulder David G. Hartman Jerry A. Hausman James J. Heckman Patric Hendershott Thomas 0 . Horst Mervyn A. King Laurence J. Kotlikoff Lawrence B. Lindsey Charles E. McLure, Jr. Peter Mieszkowski Joseph J. Minarik Richard A. Musgrave

Joseph A. Pechman Michael Salinger Robert J. Shiller John B. Shoven Joel Slemrod Joseph E. Stiglitz Lawrence H. Surmers John Whalley David Wise

\section{Affiliation}

The Brookings Institution

Harvard University

University of Maryland

Stanford University

National Bureau of Economic Research Harvard University and NBER

University of Washington

Princeton University

U.S. Department of the Treasury

Bell Laboratories

Stanford University

Harvard University

Massachusetts Institute of Technology

Unversity of Chicago

Purdue University

U.S. Department of the Treasury

University of Birmingham, England

Yale University

Harvard University

National Bureau of Econornic Research University of Houston

The Brookings Institution

Harvard University of the University of California at Santa Cruz

The Brookings Institution

Massachusetts Institute of Technology

University of Pennsylvania

Stanford University

University of Minnesota

Princeton University

Massachusetts Institute of Technology

University of Western Ontario

Harvard University 


\title{
ABSTRACT
}

Modern work in labor supply attempts to account for nonlinear budget sets created by government tax and transfer programs. Progressive taxation leads to nonlinear convex budget sets while the earned income credit, social security contributions, AFDC, and the proposed NIT plans all lead to nonlinear, nonconvex budget sets. Where nonlinear budget sets occur, the expected value of the random variable, labor supply, can no longer be calculated by simply 'plugging in' the estimated coefficients. Properties of the stochastic terms which arise from the residual or from a stochastic preference structure need to be accounted for. This paper considers both analytical approaches and Monte Carlo approaches to the problem. We attempt to find accurate and low cost computational techniques which would permit extensive use of simulation methodology. Large samples are typically included in such simulations which makes computational techniques an important consideration. But these large samples may also lead to simplifications in computational techniques because of the averaging process used in calculation of simulation results. This paper investigates the tradeoffs available between computational accuracy and cost in simulation exercises over large samples.

\author{
Jerry A. Hausman \\ Department of Economics \\ Mass. Institute of Technology \\ Room E52-271A \\ Cambridge, MA. 02139 \\ Telephone 617/253-3644
}




\section{INTRODUCTION}

Suppose that we have successfully estimated a structural model of labor supply. Given the large amount of public interest in the question of income tax reform, an important use of the estimated model would be to assess the possible effects on labor supply, tax revenue, and individual welfare of proposed reforms. These evaluations are sometimes performed using local elasticity estimates. However, such a simplified analysis may not be very accurate for the rather large changes contemplated in many tax reform proposals. Another problem which arises with simplified elasticity calculations is that they often ignore the considerable heterogeneity of the population response. A better approach would seem to be to use the estimated structural model to predict the effect of the tax changes. Thus, we would need to derive analytically the statistical expectation of the population response under the proposed changes; or if analytical derivation proves to be mathematically intractible, a Monte Carlo approach would provide the results.

But an important potential problem arises when such simulations are conducted. This problem arises because of the nonlinear, and often nonconvex, budget sets which arise due to progressive income taxation as well as other tax and transfer policies. In a nonlinear econometric model with nonlinearities of this type, it is not necessarily the case that the sources of stochastic variation have an additive zero expectation term within a simulation exercise. Nor is it the case that such effects are small, necessarily, since ' $R{ }^{2}$ ' $s$ ' in labor supply models are typically not that high, i.e., much unexplained residual variation remains after the model has been specified and estimated. Thus, for a particular individual we might well expect that careful treatment of the stochastic specification in calculating the appropriate expectation would be quite important. Yet for the population at large, or equivalently a very large 
sample, the importance of the stochastic components is unclear. In the sample if the variation of the exogenous variable is sufficiently large and the fit of the equation sufficiently good, the effect of the stochastic component may be small. Perhaps a more promising approach is to realize that extremely accurate computation for each individual may not be needed, because a law of large numbers type result may hold for the entire sample. That is, rather crude computational techniques may be used for each individual, but the sample mean values can still be quite accurate. Significant computational savings occur because say only one Monte Carlo draw is done for each individual. While the variance of the predicted response of that given individual may be large, in the complete sample the large variance may not be important due to a large number type of averaging. This type of technical question is the major focus of this paper.

The plan of the paper is as follows. In section I we outline the problem of labor supply with nonlinear budget constraints. I also specify and use estimates of a linear supply model. This section and the estimates follow from Hausman (1979). In section II the stochastic problems which arise in simulation of nonlinear budget set models are studied. Both analytical and Monte Carlo approaches are considered. Comparative statistics for computer times are given to indicate potential savings from the use of simple computational techniques. Then, in Section III I consider tax reform proposals. The type of tax reform proposal considered, is a reduction of tax rates by $10 \%$ to $30 \%$. Here we consider not on ly labor supply effects and welfare effects, but we also look at tax revenue considerations. It is important to emphasize at the outset that all 
analysis takes place within a partial equilibrium framework. Thus, general equilibrium effects which might be quite important, especialiy in long-run response, are not treated. 
The essential feature which distinguishes econometric models of labor supply with taxes from traditional demand models is the non-constancy of the net, after tax wage. Except for the case of a proportional tax system, the net wage depends on hours worked because of the operation of the tax system. Also, the marginal net wage depends on the specific budget segmenc that the individual's indifference curve is tangent to. Thus, econometric techniques need to be devised which can treat the nonlinearity of the budget set. An econometric model needs to take the exogenous nonlinear budget set and to explain the individual choice of desired hours. We first describe such a model for convex and nonconvex budget sets. As expected, the convex case is simpler to deal with. We then consider other issues of model specification such as variation in tastes, and fixed costs to working.

Econometric estimation is quite straightforward in the case of a convex budget set. Convex budget sets occur due to the operation of a progressive tax system. Let us first analyze the simplest case, that of a progressive tax on labor income so that the marginal tax rate is non-decreasing. In figure 1.1 three marginal tax rates are considered, $t_{1}, t_{2}, t_{3}$, which lead to three aftertax net wages, $w_{1}, w_{2}, w_{3}$, where $w_{i}=w\left(1-t_{i}\right) . y_{1}$ denotes non-1abor income. $H_{1}$ and $\mathrm{H}_{2}$ correspond to kink point hours which occur at the intersection of two cax brackets. But an important addition to the diagram are the "virtual" incomes $y_{2}$ and $y_{3}$, which follow from extension of a given budget segment to the vertical axis. They are denoted as virtual income because if the individual faced the linear budget set $B_{2}=\left(w_{2}, y_{2}\right)$, he would still choose hours of work $h^{*}$ as in figure 1.1. An important property of such convex budget sets in the presence of strictly quasi-concave preferences, is that only one tangency (at most) will exist between the individual indifference curves and the budget set. Hausman 


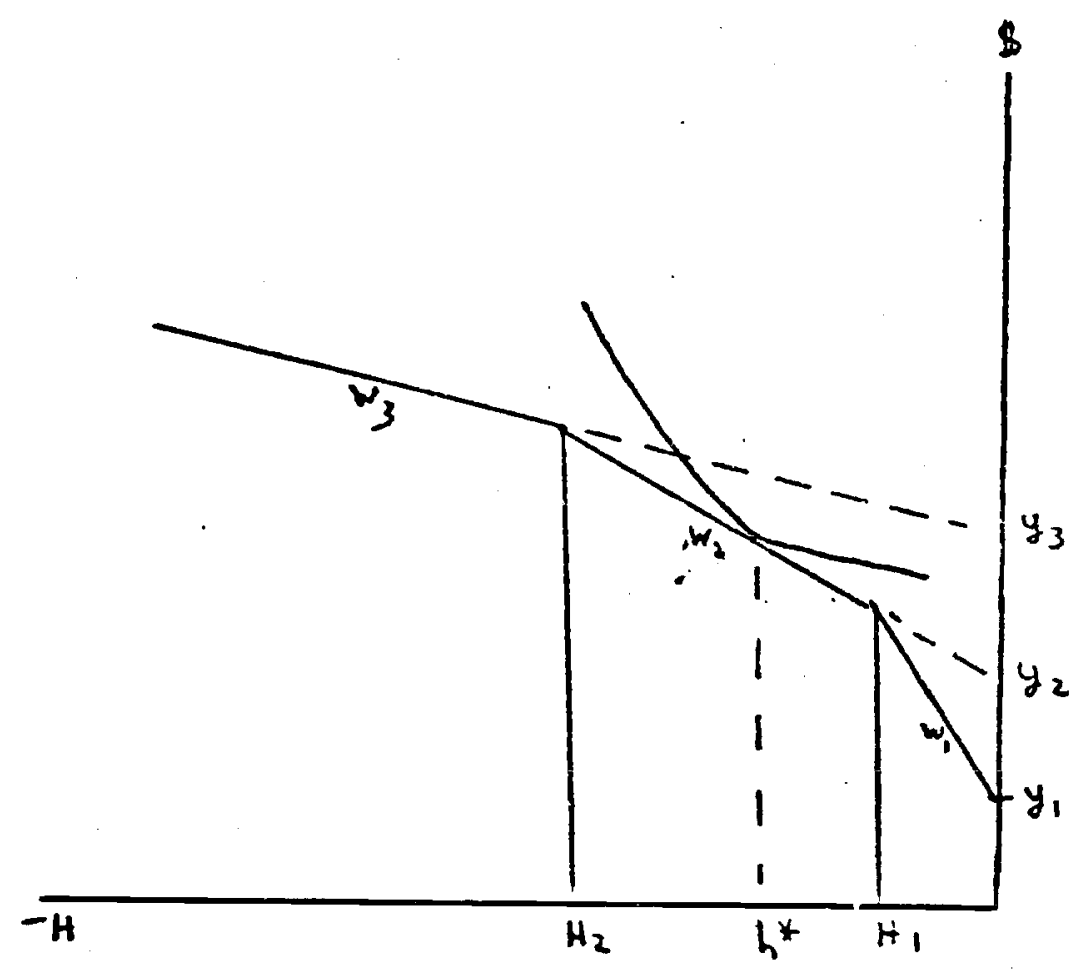

Figure 1.1

(1979b) uses this result to demonstrate that only a specification of the labor supply function is necessary for estimation. The form of the underlying utility function is not necessary.

Since a unique tangency or a corner solution at zero hours will determine desired hours of work, we need only determine where the tangency occurs. To do so we begin with a slight generalization of the usual type of labor supply specification

$$
h=\tilde{g}(w, y, z, \beta)+\varepsilon=h *+\varepsilon
$$

where $w$ is a vector of net wages, $y$ is a vector of virtual incomes, $z$ are individual socioeconomic variables, $\beta$ is the unknown vector of coefficients assumed fixed over the population, and $\varepsilon$ is a stochastic term which represents the divergence between desired hours $h^{*}$ and actual hours. The typical specification that has been used in $\tilde{g}()$ is linear or $\log 1$ inear and scalar w and $y$ corresponding to the market wage and nonlabor income. The stochastic term is assumed to have classical properties so that no quantity constraints on hours 
worked exists. However, $0 \leqq \mathrm{~h} \leqq \overline{\mathrm{H}}$ where $\mathrm{H}$ is a physical maximum to hours worked. We also assume that when the $\beta^{\prime}$ s are estimated that the slutsky conditions are satisfied so that $\tilde{g}($ ) arises from concave preferences. .

The problem to be solved is to find $h^{*}$ when the individual is faced with the convex budget set, $B$ for $i=1, \ldots, m$. To find $h^{*}$ we take the specification of desired hours on a given budget segment $B_{i}$

$$
h_{i}^{*}=g\left(w_{i}, Y_{i}, z, B\right)
$$

Calculate $h_{1}^{*}$ and if $0 \leqq h_{1}^{*} \leqq \mathrm{H}_{1}$ where the $\mathrm{H}_{i}^{\prime}$ s are kink point hours in figure 1.1 then $h_{1}^{*}$ is feasible and represents the unique tangency of the indifference curves and the budget set. If $h_{1}^{*} \leqq 0$, then zero hours is the desired amount of work. However, if $h^{*}$ exceeds $\mathrm{H}_{1}$ it is not feasible so we move on to try the next budget segment. If $\mathrm{H}_{1} \leqq \mathrm{~h}_{2} \leqq \mathrm{H}_{2}$ we again would have the unique optimum. If we have bracketed the kink point so that $\mathrm{h}_{1}^{*}>\mathrm{H}_{1}$ and $\mathrm{h}_{2}^{*}<\mathrm{H}_{1}$, then $\mathrm{h}^{*}=\mathrm{H}_{1}$ so that desired hours fall at the kink point. Otherwise we go on and calculate h*. By trying out all the segments we will either find a tangency or find that $h_{i}^{\star}>H_{i}^{\star}$ for all $i$ in which case $h^{*}=\bar{H}$. Then a nonlinear least squares procedures or Tobit procedure to take account of minimum at zero should be used to compute the unknown $\beta$ parameters. The statistical procedure would basically minimize the sum of $\sum_{j=1}^{N}\left(h_{j}-h_{j}^{*}\right)^{2}$ where $j$ represents individuals in the sample. Perhaps a better technique would be to use Toblt which enforces the constraint that $h_{j} \geq 0$. The case of the nonconvex budget is more complicated because equation (1.2) can lead to more than one feasible tangency which leads to many potential $h_{1}^{*} s$. Non-convex budget sets arise from the presence of government transfer programs. The four most important programs of this type are low income tax credit, AFDC, Social security benefits, and a negative income tax (NIT) program. In Figure 1.2 we indicate a common type of non-convex budget set. In Figure 1.2 we have two tangencles of the indifference curve with the budget set which seems to lead 
to two potential $\underset{i}{\mathrm{~h}}$ 's.

$h_{i}^{*}$ s.

$-H$

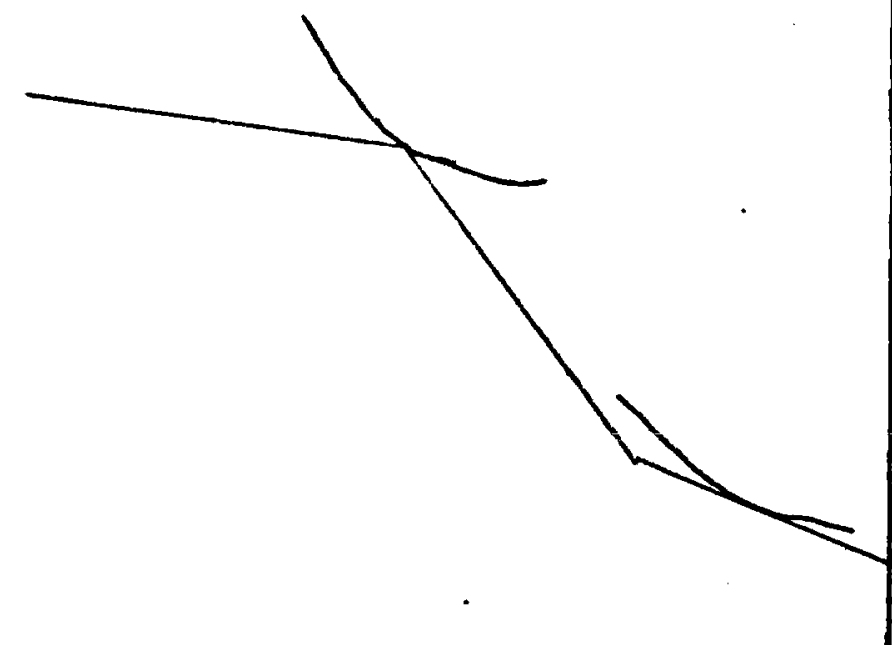

Figure 1.2

How can we decide which of these feasible $h_{i}^{* \prime s}$ is the global optimum? Burtless-Hausman (1978) initially demonstrated the technique of working backwards from the labor supply specification of equation $(2.2)$ to the underlying preferences which can be represented by a utility function. The basic idea to make use of Roy's identity which generated the labor supply function from the indirect utility function $v\left(w_{i}, Y_{i}\right)$

$$
\frac{\partial v\left(w_{i}, y_{i}\right)}{\partial w_{i}} / \frac{\partial v\left(w_{i}, y_{i}\right)}{\partial y_{i}}=h_{i}^{*}=g\left(w_{i}, y_{i}, z, \beta\right)
$$

along a given budget segment. So long as the slutsky condition holds then $\nabla\left(w_{i}, Y_{i}\right)$ can always be recovered by solving the differential equation (2.3). In fact, $v($ ) often has a quite simple closed form for commonly used labor supply specifications. 
For the linear supply specification $h_{i}^{*}=\alpha w_{i}+B y_{i}+z_{\gamma}$, which is used in this paper, Hausman (1979a) solved for the indirect utility function

$$
v\left(w_{i}, y_{i}\right)=e^{\beta w_{i}}\left(y+\frac{\alpha}{\beta} w_{i}-\frac{\alpha}{\beta^{2}}+\frac{z Y}{\beta}\right)
$$

Given the indirect utility function, all of the feasible tangencies can be compared, and the tangency with highest utility is chosen as the preferred hours of work, $h^{\star}$. Then as with the convex budget set case, we can use either nonlinear least squares or a Tobit procedure to estimate the unknown coefficients. While using a specific parameterization of the utility function seems upsetting to some people, it should be realized that writing down a labor supply function as in equation (1.2) is equivalent to writing down a utility function under the assumption of utility maximization. To the extent that the labor supply specification yields a robust approximation to the data, the associated utility function will also provide a good approximation to the underlying preferences. The utility function allows us to make the global comparisons to determine the preferred hours of labor supply. The convex case needs only local comparisons, but the nonconvex case requires global comparisons because of the possiblility of multiple tangencies of indifference curves with the budget set.

We next introduce the possibility of variation in tastes. In the labor supply specification of equation (1.1), all individuals are assumed to have identical $\beta^{\prime}$ s so that variation of observationally equivalent individuals must arise solely from $\varepsilon$. However, empirical studies seem to do an inadequate job of explaining observed hours of work under the assumption of the representative individual. Burtless-Hausman (1978) allowed for variation in preferences by permitting $\beta$ to be randomly distributed in the population. Their results 
Indicated that variation in $\beta$ seemed more important than variation in $\alpha$. They also found that variation in $\beta$ represented approximately 8 times as much of the unexplained variance as did variation in $\varepsilon$. An even more satisfactory procedure would be to allow all the taste coefficients to vary in the population. At present the requirement of evaluating multiple integrals over nonrectangular regions for the more general specification has led to the use of the simple case of one or two taste coefficients varying. Further research is needed to determine whether this more complex specification would be an important improvement over current models.

Another consideration which can have an important effect on the budget set for women's labor force participation is fixed costs to working. Transportation costs, the presence of young children, and search costs of finding a job can lead to a fixed cost element in the labor supply decision. The basic effect of fixed costs is to introduce a nonconvexity in the budget set at the origin. Thus, even if the original budget is convex as in Figure 1.1 the presence of fixed costs leads to a minimum number of hours $\mathrm{H}_{0}$, which depends on the wage, below which an individual will not choose to work. In figure 1.3 nonlabor income is $y_{1}$ with the

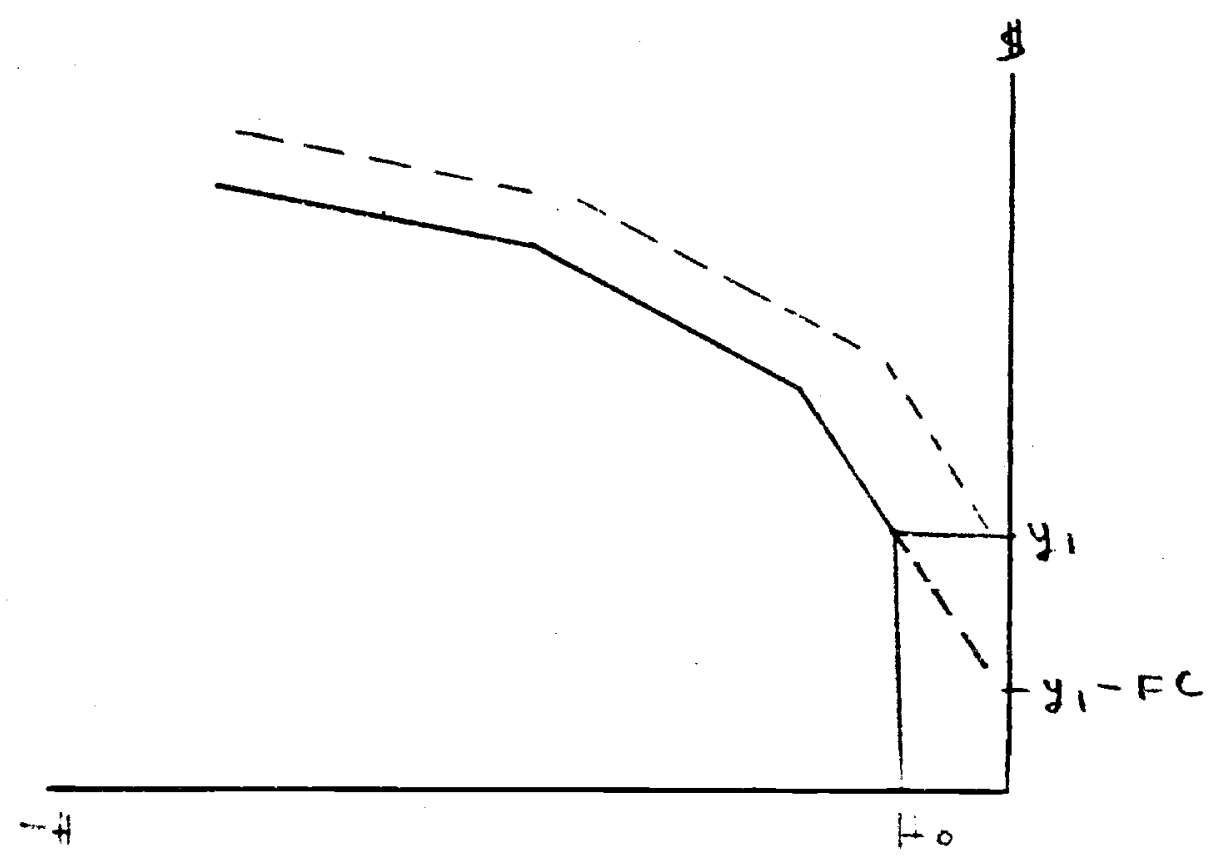

Figure 1.3 
original convex budget set $\mathrm{drawn}$ by the dotted line. However, the presence of fixed costs lowers the effective budget set to the point $y_{1}-F C$. The individual would not choose to work less than $\mathrm{H}_{0}$ hours because she would be better of $f$ at zero hours. This nonconvexity invalidates the simple reservation wage theory of labor force participation since hours also need to be accounted for. Hausman (1979a) in a labor force participation study of welfare mothers found average fixed costs to be on the order of $\$ 100$ per month. The importance of fixed costs could explain the often noted empirical fact that very few individuals are observed working less than 10 or 15 hours per week.

We estimated a model of labor supply (Hausman (1979)) which takes full account of the effect of taxation for two groups in the population. The labor supply of husbands and wives is considered for 1975 for a sample from the Michigan Income Dynamics Data. Budget sets were constructed using both federal and state tax regulations, c.f., Hausman (1979). It is important to note that we did not have access to actual cax return data. Instead, we impuced deductions beyond the standard deduction using population averages. At present no data source has both all the necessary labor supply data in addition to actual income tax return information. ${ }^{1}$ At the current stage of model development only a single person can be considered so that the husband was created as the primary worker in a family with the wife as the secondary worker. A model which allows for joint family labor supply decisions seems the obvious next goal of our researtch. For both husbands and wives we consider each of two cases: a convex budget set where the effects of FICA, the earned income credit, and the standard deduction are averaged to produce a convex budget set and a complete nonconvex budget set where the effect of each program is to introduce a nonconvexity.

Along each segment the basic labor supply model which is used is linear in the wage and virtual income 


$$
\text { (1.5) } \quad h_{i}^{*}=\alpha w_{i}+B y_{i}+z \gamma
$$

where $h_{i}$ is desired hours, $w_{i}$ is the net wage on segment $i, y_{i}$ is virtual income for segment $i$, and $z$ are socioeconomic variables. For fixed $\alpha, \beta$, and $\gamma$ desired hours h* may not be feasible since h*i may be greater than or less than the hours at the end points of the budget segment $H_{i-1}$ and $H_{i}$. If desired hours are feasible than we have a tangency of the indifference curve and the budget segment. In the case of a convex budget set this tangency is unique, and we then use our stochastic specification for the deviation of actual hours from desired hours for person $\mathrm{j}$ as

(1.6) $h_{j}=h_{i j}^{*}+\eta_{j}$

Since observed hours $h_{j} \geqq 0$ the stochastic term $\eta_{j}$ is assumed to be independent truncated normal across individuals in the population. Thus, we have a Tobit specification for the hours worked variable. However, if $h \stackrel{i}{j}=0$ we assume that the individuals do not choose to work and so set $\mathrm{h}_{\mathrm{j}}=0$ also. Since the final model has two sources of stochastic variation the interpretation of $\eta_{j}$ differs from standard models. Here we picture the individual faced by a choice from a set of jobs which differ in normal (long run) hours worked. He chooses that job closest to his $h^{*} j$. But observed $h_{j}$ may differ due to unexpected layoffs, short time, overtime, or poor health. As an empirical matter we find the standard deviation of $\eta_{j}$ to be reasonably small which indicates that individuals are successful in matching jobs to their desired hours of work. ${ }^{a}$

If the budget set is non-convex $h * j$ is not necessarily unique because multiple tangencies can occur between the indifference curves and the budget set. Then $h_{i j}^{*}$ is chosen as the tangency which lead to maximum utility which is determined by use of the corresponding indirect utility function from equation (1.4) We again use the stochastic specification of equation (1.6) to express the deviation of actual hours from desired hours of work. It is interesting to 
note that although certain kink points such as $\mathrm{H}$ in Figure 1.2 in the non-convex case cannot correspond to desired hours, we might still observe them as actual hours or work due to the stochastic term $\eta_{j}$ in the model.

The second source of stochastic variation in the model arises from a distribution of tastes in the population. In line with our previous research we specify to be a truncated normal random variable which falls in the interval $(-\infty, 0)$. An upper limit of zero is specified since we assume that leisure is a normal good. Thus, as $B$ ranges over the permissable interval there is a certain probability that any amount of hours corresponds to desired hours. As an empirical matter $\beta$ turns out to be the major source of stochastic variation in the model which confirms our previous findings reported in Burtless-Hausman $(1978) .^{2}$

The estimated results for husbands are presented along with asymptotic standard errors in Table 1.1. The coefficients are generally estimated quite precisely, especially the wage and non-labor income coefficients. The socioeconomic variables have coefficients of reasonable magnitude except the house equity which perhaps reflects factors in the mortgage credit market and the special tax treatment of houses. We first note that the uncompensated wage coefficient is essentially zero. Not only is the estimate close to zero but the estimated standard error is quite small. In the extreme case of two standard deviations from the estimate for the nonconvex case, a change in the net wage of $\$ 1.00$ along a budget segment leads to an expected increase in annual hours worked of 32.5 which is less than $2 \%$ of the sample mean. The expected change in hours is only 11.3 while in the convex case the expected change in annual hours is .2 . The finding of an extremely small uncompensaced wage effect is in accord with the previous empirical findings. Thus the direct effect of income taxation which reduces the net wage has almost no effect on hours worked among husbands. 
TABLE 1.1 HUSBANDS ANNUAI HCURS OF WORK (THOUSANDS)*

Variable

1. $\mu_{B}-$ Non-labor income (1000's)

2. $\sigma_{B}$

3. Wage

4. Constant

5. Children under 6

6. Family size

7. (Age $-45,0)$

8. House equity (1000's)

9. Bad Health

10. $\sigma_{n}$

11. Mean $B$

12. Standard Deviation of $B$

13. Median of $B$
Convex Nonconvex

$$
2.037
$$

(.0729)

1.061

$(.245)$

$\begin{array}{ll}.6242 & .4541 \\ (.0234) & (.0570)\end{array}$

\begin{tabular}{|c|c|}
\hline$(.0002)$ & $\begin{array}{c}.0113 \\
(.0106)\end{array}$ \\
\hline $\begin{array}{l}2.4195 \\
(.0589)\end{array}$ & $\begin{array}{l}2.366 \\
(.153)\end{array}$ \\
\hline
\end{tabular}

$-.0039$

.0113

$(.0255)$

$(.0635)$

.0341

(.0170)

.0657

(.0310)

$-.0011$

(.0108)

$-.0055$

(.0235)

$(.0026$

.0036

$(.0008)$

$-.1387$

$(.1436)$

$-.0520$

$(.564)$

.2794
$(.0178)$

.2862

(.0540)

$-.166$

$-.153$

.156

.141

$-.120$

$-. .113$

* Asymptotic standard error are presented below each estimatea coefficient. 
However, our results do differ from previous studies in indicating a significant income effect. Remember that we allow a distribution of preferences in the population. The estimated probability density for the nonconvex case is shown in Figure 1.4. The distribution has substantial skewness since it is the extreme left tail of the truncated normal distribution with the standard deviation approximately equal to the mean in magnitude. This finding is repeated in the convex case with the skewness even more pronounced. My previous work has also found this general form even when different probability densities are used, e.g., Hausman (1979a) where a Weibull density is used. The underlying parameters of the preference distribution are estimate quite precisely so that the finding is not likely to be an accidental occurence. $f(\beta)$

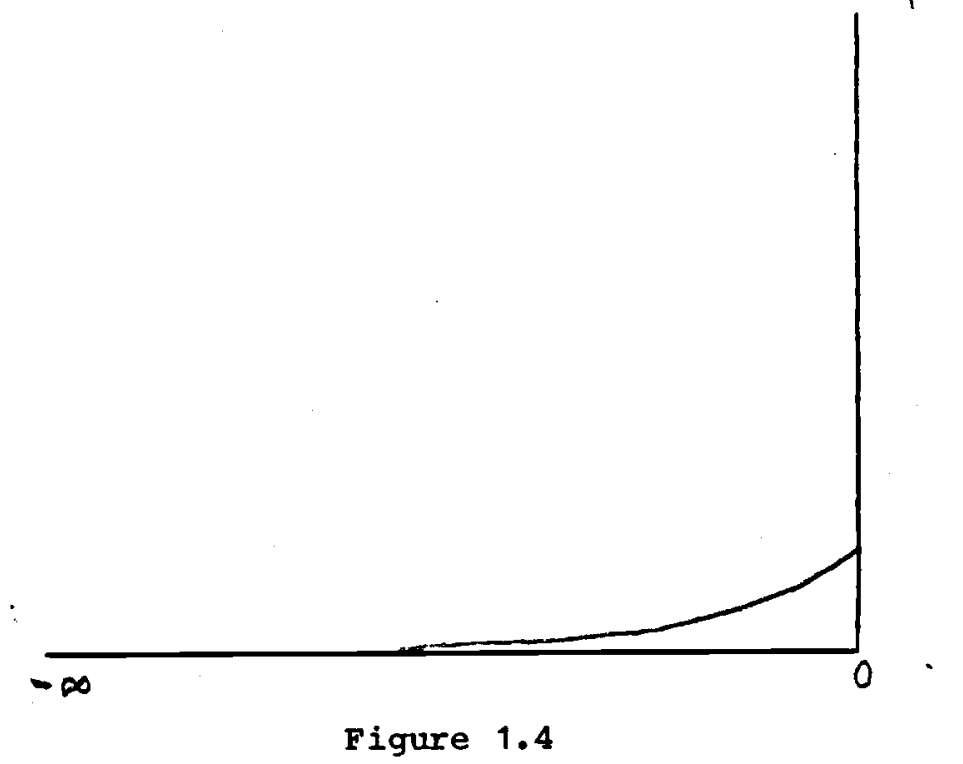

Next we present the empirical results for a sample of married women. Our sample consists of the wives of the males used in the previous section. Previous research has indicated that married womens' labor supply decisions are sensitive to the net wage so that we would expect to find that taxes create both an important uncompensated wage effect and an income effect as they do for husbands. As we previously stated, we treat wives labor supply decisions conditional on husband's earned income. Thus, wives are considered to be 
secondary workers which may not be a proper assumption. Since in our sample labor force participation of husbands is near 1008 while wives is near 508 perhaps treating wives earnings conditional on husbands earnings is not a particularly bad assumption. However, the crucial question is whether husbands earnings should enter the wives labor supply decision as exogenous non-labor income. It is probable that some jointness in decision making takes place when the husband adjusts his hours of work to his wife's earnings. A family labor supply model would be able to treat these problems better, but here we only provide estimates for the conditional model.

We turn now to the estimates of the labor supply equations which are presented in Table 2.2. We present estimates for a convexified budget set, for the complete nonconvex budget set, and for a nonconvex budget set with fixed costs included. First note that we find substantial uncompensated wage and income elasticities. For the average woman who is working full time we find the uncompensated wage elasticity to be .995 for the nonconvex results and a similar magnitude for the convex results, .978 , is found. When fixed costs are added the uncompensated wage elasticity falls to .9065 . Thus, all three estimates indicate that the effect' of the income tax in decreasing the after tax, net wage is important in determining wives labor supply. Since wives net wage is lowered substantially by the presence of the 'marriage tax' the tax effect may be much greater than if wives earnings were not added to husbands earnings for tax purposes. On the other hand, we also find an important effect of non-labor income (and actual income). The elasticity at the means is approximately -.2 . This effect causes larger labor supply by wives because their husbands earnings are reduced by taxes. The two effects have opposite sign so that a simulation is needed to evaluate the net effect of the marriage tax.

In this section we have presented our specification of labor supply in the 
Table 1.2 Wives Annual Fours (Thousands)

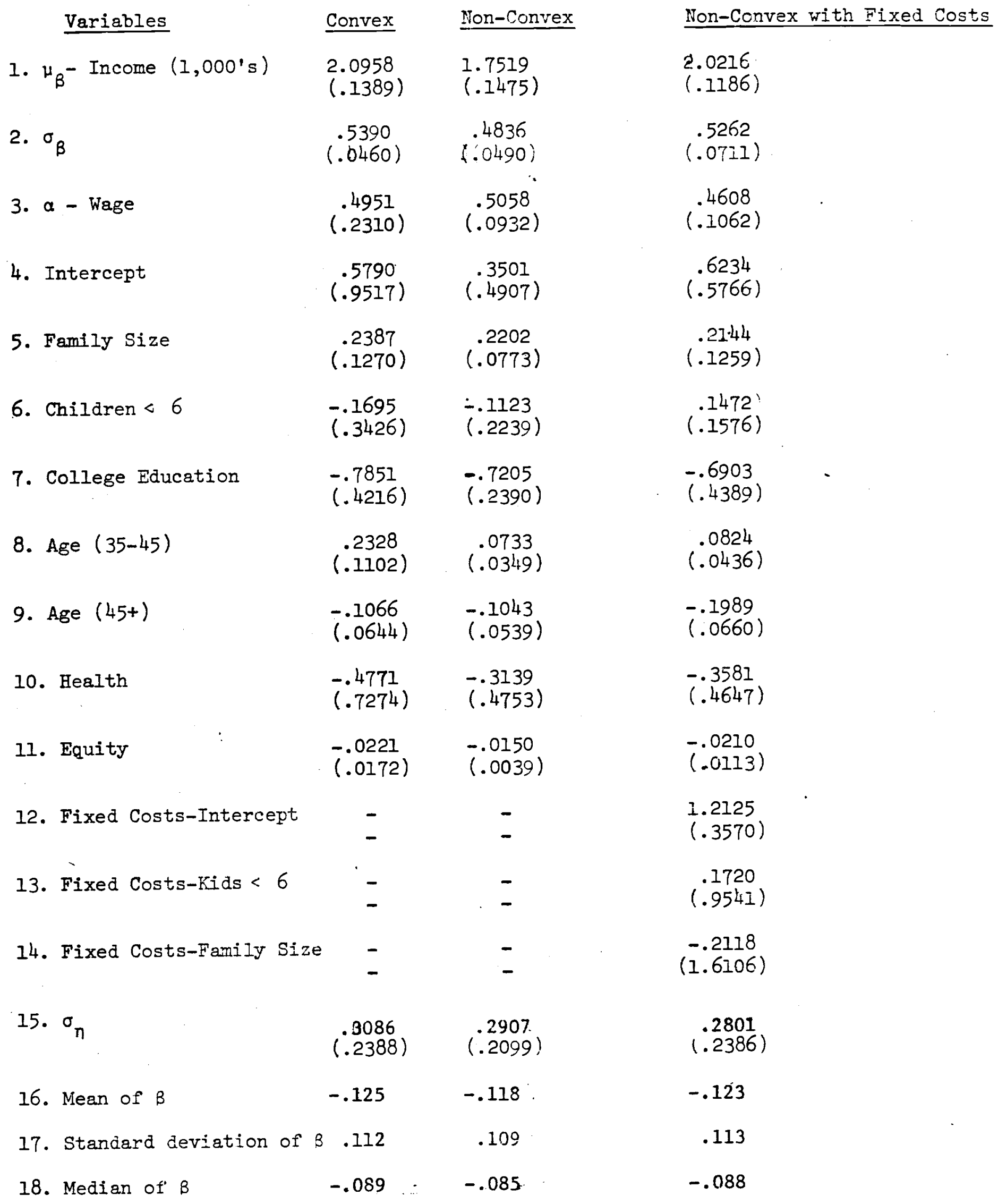


presence of nonlinear convex budget sets and nonconvex budget sets. The stochastic specification has been emphasized since it will play an important role In the simulation results. We now consider how the results can be used to simulate the effects of tax reform. We emphasize computational considerations so that the simulations can be conducted at low or moderate costs of computer time. 


\section{Tax Change Evaluation}

In this section we develop formulae for expected hours of work, expected tax revenue, and expected deadweight loss given our model of labor supply and the estimates of the previous section. The main question that we attempt to answer in this section is how much attention must be paid to the stochastic components of the specification to obtain accurate estimates. We consider both analytical and Monte Carlo approaches to the problem. We want to find accurate and low cost computational techniques which permit use of simulation methodology. At the same time keep in mind the typically large samples which are involved in a simulation. These large samples make computational techniques an important consideration. But the large samples may also allow possible simplifications in computational techniques because of the averaging process used in calculation of simulation results.

For a given person $j$ the desired hours of work on budget segment is specified to be

(2.1) $h_{i j}=\alpha w_{i j}+\beta y_{i j}+z_{j}^{\gamma}+\eta_{j}=h_{i j}^{*}+n_{j}$

where $w_{i j}$ is the net, after tax wage on segment $i$ and $y_{i j}$ is virtual income for segment $i, i . e .$, the intercept of segment $i$ extended back to the vertical axis in Figure 1.1. The vector $\mathrm{z}_{j}$ represents socibeconomic characteristics of individual $j$. Now if $w_{i j}$ and $y_{i j}$ were determined exogenously and $\alpha, \beta, \gamma$ were fixed coefficients, then we could use the standard inear expectation rules to derive $\mathrm{Eh}_{i j}=\alpha w_{i j}+\beta y_{i j}+z_{j} \gamma$. of course, we specify $\beta$ to be distributed randomiy in the population in the intervals $(-\infty, 0)$. But the extension to stochastic $B$ does not create much difficulty because again give exogenous $w_{i j}$ and $y_{i j}$ we would

$$
\begin{aligned}
E h_{i j}=\alpha w_{i j}+y_{i j} E \beta+z_{j}^{\gamma} & =\alpha w_{i j}+\left(\mu_{\beta}-\sigma_{\beta}\left[\frac{\Phi\left(\mu_{\beta} / \sigma_{\beta}\right)}{1-\Phi\left(\mu_{\beta} / \sigma_{\beta}\right)}\right]\right) y_{i j}+z_{j} \\
& =\alpha w_{i j}+\overline{B y}_{i j}+z_{j}^{\gamma}
\end{aligned}
$$


where $\mu_{B}$ and $\sigma_{B}$ are the underlying parameters of the non-truncated distribution for $\beta$, respectively, while $\phi$ and $\Phi$ are the standard normal density function and distribution function, respectively. The problem to be faced, then, is that $w_{i j}$ and $y_{i j}$ are determined by the budget segment $B_{i j}$ which depends on two stochastic components, $\eta_{j}$ and $\nu_{j}=B_{j}-\bar{B}$. Thus, we have the problem that the right hand side variables are not determined exogenously. Nor do we have a simple formula for their expectation as we would in the linear simultaneous equations case. Thus, not unexpectedly, we need to consider the complete budget set when calculating the conditional expectation of hours worked, tax revenue paid, or deadweight loss and account for the 'endogeneity' of $w_{i j}$ and $y_{i j}$. It turns out to be the nonlinearity of the budget set together with the distribution of preferences specification which cause the significant costs of labor supply simultaions. As we indicate below, the solution for that part of the $\beta$ distribution which corresponds to a given budget segment is a non-trivial calculation.

We first consider the analytical conditional expectation for hours worked. The expectation is

$$
\text { (2.3) } \begin{aligned}
E h_{j} & =\sum_{i=1}^{m}\left[\int_{\beta_{i-1, j}}^{\beta_{i j}} \int_{q_{i j}(\beta)}^{\infty}\left(h_{i j}^{\star}(\beta)+n_{j}\right) f\left(\eta_{j}\right) f(\beta) d n_{j} d B\right] \\
& +\sum_{i=1}^{m-1}\left[\int_{r_{i, j}}^{\infty}\left(h_{i j}^{*}+n_{j}\right)\left(F\left(\beta_{i j}\right)+F\left(\beta_{i-1, j}\right)\right) f\left(n_{j}\right) d n_{j}\right]
\end{aligned}
$$

As we discussed in the last section for $\beta<\beta_{j}^{*}$ which is the minimum $\beta$ which causes desired hours to be positive, $h_{i j}^{\star}>0$, we assume that actual hours $h_{j}=0$. Thus equation (2.3) calculate the expectation of actual hours $h_{j}$ over the range for which desired hours $h_{i j}^{\circ}$ are positive. The first sum in equation corresponds to the case where desired hours fall along a budget segment, $i=1, m$. The range of 
$\beta^{\prime}$ 's which causes this to happen are denoted $\left(\beta_{i-1, j}, \beta_{i j}\right)$. Note that in the nonconvex case some segments may have the intergral end points equal which means that desired hours will not fall anywhere on the segment. It is basically this calculation which leads to the greatest expense in simulation since calculation of the univariate and bivariate integrals is not that costly. The nonconvex budget set of figure 1.2 indicates the possibility of an indifference curve which is tangent to two budget segments simultaneously. Thus in the nonconvex case there are portions of the budget segment which cannot correspond to desired hours. For this possibility to happen, the indirecl utility function of eguation (1.4) is equal for a given $\beta$ for two sets of $w_{i}^{\prime}$ 's and $y_{i}^{\prime}$ 's. Calculation of these $B^{\prime} s$ for each nonconvexity in the budget set requires the iterative solution of a nonlinear equation. Given the further facts that the points of mutual tangency are unknown and that complete budget segments may be skipped over, the computations of the $\left(\beta_{i-1, j}, \beta_{i j}\right)$ for all budget segments $i=1, m$ is a rather complicated task. Thus, we look for possible simplifications in simulation to reduce both the computer costs and the required programming time.

The outer integral in equation (2.3) determines desired hours $h_{i j}^{*}(\beta)$. But actual hours $h_{i j}=h_{i j}^{*}(\beta)+\eta_{j}$. The inner integral accounts for this second source of stochastic variation. Note that for large negative values of $n_{j}$ we have $h_{i j}<0$. Thus $q_{i j}(\beta)=h_{i j}^{*}(\beta)$ which is the minimum value of $\eta$ which keeps actual hours positive. The second sum in equation (2.3) correspords to desired hours falling at one of the m-l curves, or kink points, of the budget set. The lower limit to the integral, $r_{i j}$, again determines the range for positive $h_{i j}$.

Evaluation of the integrals in equation (2.3) is not especially difficult, even given the bivariate integrals. Conditioning formulae can be used and known partial fraction expansions for univariate integrals lead to quick evaluation. 
These simplifications follow basically from the linear specifications of $h_{i j}$ in equation (2.1). Unfortunately, the computation of integrals becomes considerably more complicated when we want to calculate expected deadweight loss due to the nonlinearity of the expenditure function. The expenditure function which corresponds to the indirect utility function of equation (1.4) is

$$
e\left(w_{i j}, U_{j}\right)=e^{-\beta w_{i j}} U_{j}-\frac{\alpha}{\beta} w_{i}+\frac{\alpha}{B^{2}}-\frac{Z_{j}^{\gamma}}{\beta}
$$

The nonlinearity arises from $\beta$ appearing in both the exponential and in the denominators of the coefficients. For a given $\beta$ deadweight loss is measured by calculating either the compensated or equivalent variation via the expenditure function of equation (2.4) and then subtracting off compensated taxes paid, using the definition of Diamond-McFadden (1974). 3 Hausman (1979c) has demonstrated the necessity of doing the correct Hicksian measure of consumer's surplus because use of the incorrect Marshallian measure can lead to very large errors in calculation of the deadweight loss. For calculation of deadweight loss equation (2.3) is altered to account for the deadweight loss for $B^{\prime} s$ which correspond to zero hours of work. Otherwise, the general formula remains the same with the main difference that the nonlinear calculation required for deadweight loss makes computation considerably more slow than in the case of hours worked which is a linear function of $\beta$. Conditioning formulae for the integrals are no longer applicable and quadrature methods to evaluate the univariate and bivariate integrals are now required.

To evaluate computation techniques we tried four approaches listed in order of decreasing computational burden on a sample of men in 1975 from the PSID data base: 
1. Analytical evaluation, via the computer, of the integrals in equation (2.3). For the nonlinear deadweight loss calculation we took the $\tilde{B_{i j}}$ corresponding to the mean $\beta$ on the interval $\left(\beta_{i-1, j}, B_{i j}\right)$ so that complete quadrature methods were not necessary to evaluace the integrals.

2. The distribution of $\beta$ was still integrated over, but one Monte Carlo draw from a normal distribution was done for $n_{j}$.

3. The distribution of was integrated over, and $n_{j}$ was set to zero.4

4. $B$ was taken at its mean value $\bar{\beta}=\mu_{\beta}-\alpha_{\beta} \phi\left(\mu_{\beta} / \sigma_{\beta}\right) /\left[1-\Phi\left(\mu_{B} / \sigma_{\beta}\right)\right]$.

Corresponding to $\bar{B}$ we find $h_{i j}^{*}(B)$ and $\eta_{j}$ is set to zero. This technique also removes any need for integration for taxes paid or calculation of deadweight loss.

Note that the second approach leads to unbiased (or consistent) estimates of the expectation which will have more variance than the actual expectations of the first approach due to the variance created by the Monce-Carlo draws. However, we consider a sample of 200 men to see whether the appropriate law of large numbers works fast enough for this consideration not to be important. Potential bias is created by apporach (3) since the expectation of $\eta_{j}$ is positive and decreases along each segment as $B_{j}$ increases. Lastly, approach (4) creates additional bias because it runs afoul of the rule that the expectation of a nonlinear function is not equal, in general, to the. function of the expectation. Potential problems arise here for both hours of work and deadweight loss because of the nonlinearity of the budget set.

In Table 3.1 we consider the four techniques on the first five men in our simulation file to see what happens at the individual level. Column l gives actual hours, while the next three columns calculate the expectations of hours corresponding to methods (1) - (4). The next two sets of columns correspond to the expectation of taxes paid and the expectation of deadweight loss using the equivalent variation measure. 
Since method (1) leads to the correct evaluation of the expectation, it provides the standard of comparison for methods (2) - (4). For labor supply we see that method (2) leads to considerable variance, as expected. Method (3) which sets $\eta=0$ gives identical results to method (1). Method (4) which takes the mean $\bar{B}$ leads to some bias, although only a small amount. For expected taxes paid methods (3) and (4) again have bias which is somewhat larger in this case. Lastly, deadweight loss seems most sensitive to the technique which is used. Techniques (3) and (4) are off by about $7 \%$ in these calculations. Thus, our tentative conclusion for individual calculations is that for labor supply and taxes paid method (3) is probably an appropriate techniques to use. 5 However, for deadweight loss full analytical evaluation of the integrals seems necessary for accurate calculation of the expectation.

We now turn to the major use of simulation for tax changes. We simulate over a file of approximately 225 men from the PSID file to see what happens to accuracy for mean changes. This file was found large enough to capture the limiting behavior of the different evaluation methods. Note that a substantial amount of computer processing time is involved here. ${ }^{6}$ Taking the amount of time to do method (1) as unity, we find that method (2) takes .560 whille method (3) takes .500 as long and method (4) takes .360 as long. Where many simulations are done over tax files which have thousands of entries these time consideration can become quite important. Given the nonlinearity of the problem, the simulations can take up large amounts of computer time. Simulation results are given in Table 3.2 . 


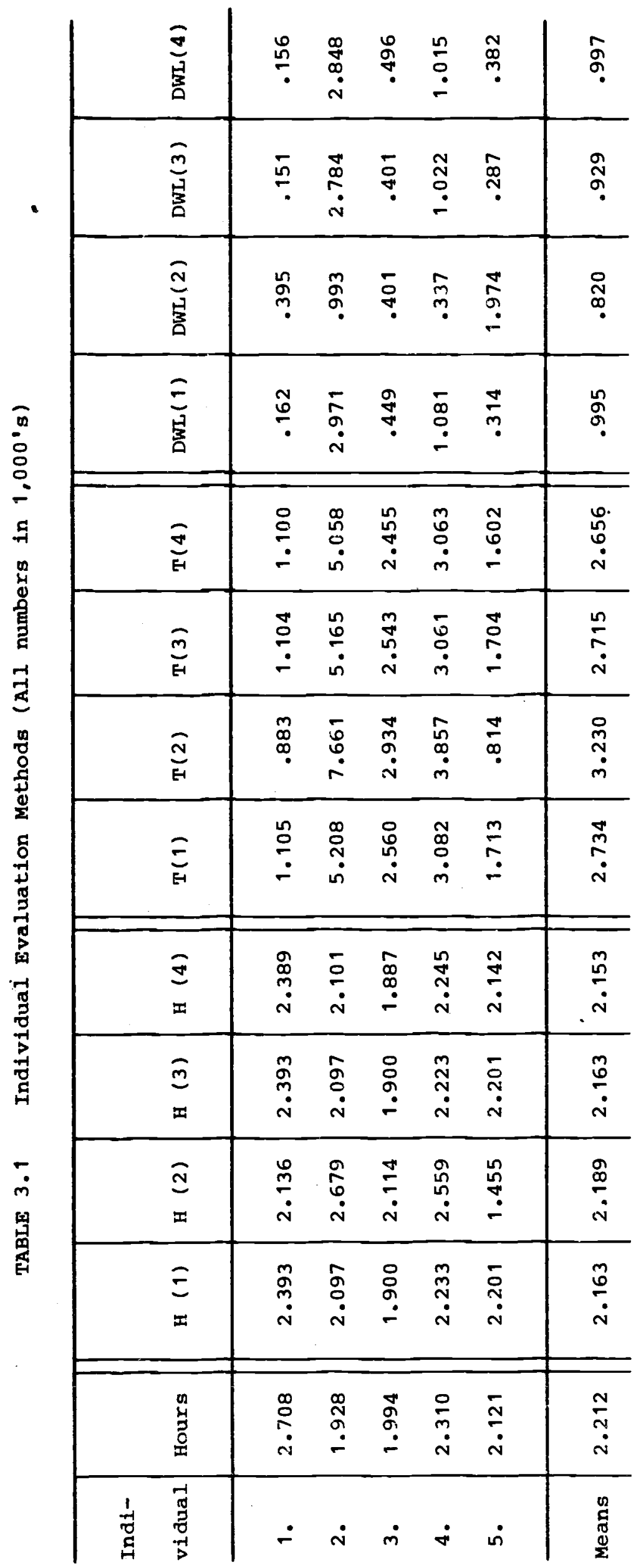


the expansions would require a full scale Monte Carlo study in itself. Yet such information might be very helpful, especially if the standard errors for the caclulations in Table 3.2 turn out to be sizable. We need to remember that "parameter uncertainty" does not average out by a large numbers type of result in simulations because of perfect correlation across sample draws in the use of parameter values. This area seems to be an important aspect of future research in the field. We now turn to evaluation of some proposed tax changes in the next section. Method (3) is used for expected hours and expected taxers while we use method (1) to evaluate expected changes in deadweight loss. 


\section{Simulation Results}

In this section we consider the effect of two different types of tax systems. The first type of tax is the current U.S. tax on labor income including both the income tax and payroll tax. We compare it to a no tax situation. To measure the change in labor supply we calculate the change in expected hours of work using equation (2.3). The appropriate choice for the change in individual welfare is not quite as clear. We use the equivalent variation calculated from the expenditure function of equation (2.4). Choice of the equivalent variation as the measure of deadweight loss, or the excess burden of taxation, seems appropriate since we later consider changes from the current system to an altered tax system. Since in the altered tax system, individual welfare may be higher, we want to know the cost (in utility) of staying with the current system. But two possible objections to our measure is that we aggregate across individuals, giving each individual the same weight in the implicit social welfare function, and that different individuals are allowed different coefficients in their expenditure functions. The problems created for analysis of vertical equity considerations by these choices are discussed in Atkinson-Stiglitz (1976). The latter problem may not be especially serious since paramter differences arise from a distribution of preferences which is common to the entire population.

The other type of tax system that we consider is a cut in tax rates of a given percentage. We consider the expected change in labor supply, the expected change in tax revenue, and the expected change in deadweight loss from the current system. Much recent attention has focussed on the revenue effects of a change in the income tax rates. It is important to note that our analysis is wholly partial equilibrium in nature. We look only at changes in expected labor supply. Thus potentially important factors such as changes in market wages and changes in inputs of other factors of production are not considered. A more complex general 
equilibrium model is needed to answer these questions. Also since tax revenues will be decreasing, the problem of compensation arises. The problem of potential versus actual compensation was the basis of the Kaldor-Hicks-Scitovsky-Samuelson -Little debate of the 1940's. Without the choice of an explicit social welfare function we cannot resolve this problem. But we assume no post-cax redistribution of income among individuals, since such actual (rather than potential) compensation is unlikely to take place.

In Table 3.1 we lool: at the effect of the current cax system for five categories defined by the market wage ${ }^{7}$ Overall, we find that the tax system decreases labor supply by $8.5 \%$ and the mean deadweight loss as a proportion of tax revenue raised is $28.7 \%$. We note important differences among the five categories.

Table 3.1 Mean Tax Results for Husbands

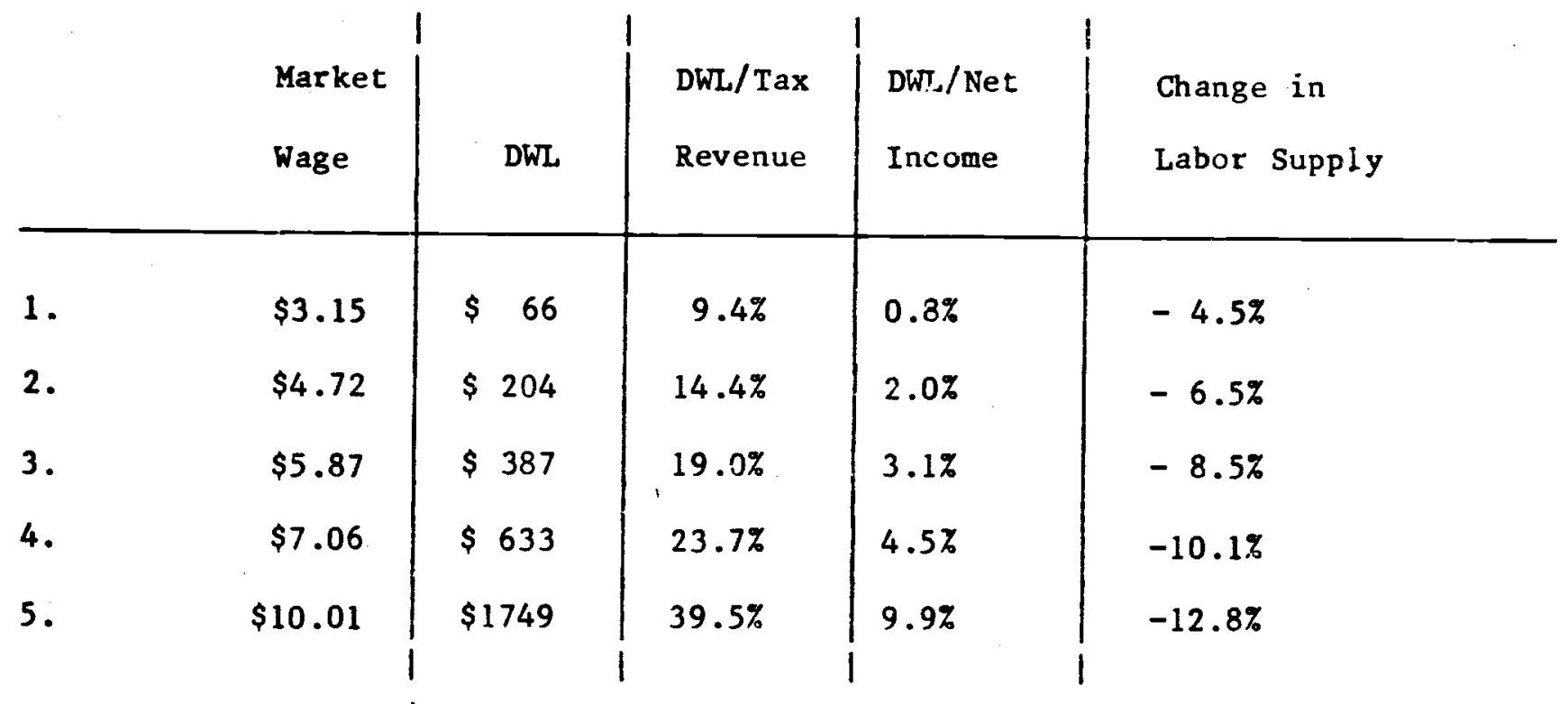


First, we see that deadweight loss rises rapidly with the market wage as we expected. In terms of the welfare cost of the tax we see that the ratio of deadweight loss to tax revenue raised starts at $9.4 \%$ and $r$ ises to $39.5 \%$ by the time we reach the highest wage category. We see that the cost of raising revenue via the income and payroll taxes is not negligible. In terms of a distributional measure we see that the ratio of deadweight loss to net income also rises rapidly. In fact, this measure indicates that individuals in the highest wage category bear a cost about 10 times the lowest category while individuals in the second highest category bear a cost 5 times as high. Without a specific social welfare measure, we cannot decide whether the current tax system has too much, too little, or about the right amount of progressiveness. But the measures of Table 3.1 seem an important step in thinking about the problem. Lastly, note that the change in labor supply from the no tax situation again rises with the wage category. The high marginal tax brackets have a significantly greater effect on labor supply than do the low tax brackets.

We now do a similar set of calculations of our sample of wives. While we found both significant deadweight loss and an important effect on labor supply for husbands compared to the no tax situation, the situation is more complicated for wives. First, about half of all wives do not work. In the absence of an income tax, the net wage would rise causing some of them to decide to work and others to increase their labor supply. But, at the same time their husbands' after tax earnings would also rise which has the opposite effect on labor force participation. Thus, both effects must be accounted for in considering the effects of the income tax. 
Table 3.2 Mean Tax Results for Wives

\begin{tabular}{ll|l|l|l|l} 
& Market & & & & \\
& Wage & DWL & RWL/Tax & DWL/Net & Change in \\
Levenue & Income & Labor Supply \\
\hline 1. & $\$ 2.11$ & $\$ 23$ & $4.6 \%$ & $.3 \%$ & $+31.2 \%$ \\
2. & $\$ 2.50$ & $\$ 119$ & $15.3 \%$ & $1.3 \%$ & $-14.2 \%$ \\
3. & $\$ 3.03$ & $\$ 142$ & $15.9 \%$ & $1.5 \%$ & $-20.3 \%$ \\
4. & $\$ 3.63$ & $\$ 184$ & $16.5 \%$ & $1.7 \%$ & $-23.8 \%$ \\
5. & $\$ 5.79$ & $\$ 1283$ & $35.7 \%$ & $8.6 \%$ & $-22.9 \%$
\end{tabular}

Overall for wives, we find the ratio of deadweight loss to tax revenue to be 18.4\%. But it should be remembered that this ratio understates the effect on labor force participants alone. For labor supply, we find that taxes serve to increase labor supply in the lowest wage category, but decrease labor supply as the wage rises. Overall, they decrease labor supply by $18.2 \%$. Thus, again for wives we see that the current income tax system has both important labor supply effect and imposes a significant cost in welfare terms for raising tax revenue.

We now turn to a consideration of Kemp-Roth type tax proposals. We will consider two levels of tax cuts, 108 and 308 . The question which has been focussed on most is what effect these tax cuts would have on tax revenues. Our resuits are partial equilibrium so that general equilibrium effects are not accounted for. The main effect here arises from the change in labor supply. But increased labor also moves some individuals into higher tax brackets. Both effects need to be accounted for. In Table 3.3 we present the two Kemp-Roth simulation results. For the 108 tax deduction mean hours of labor supply for husbands rise 
Table 3.3 Kemp-Roth Tax Cut Proposals for Husbands

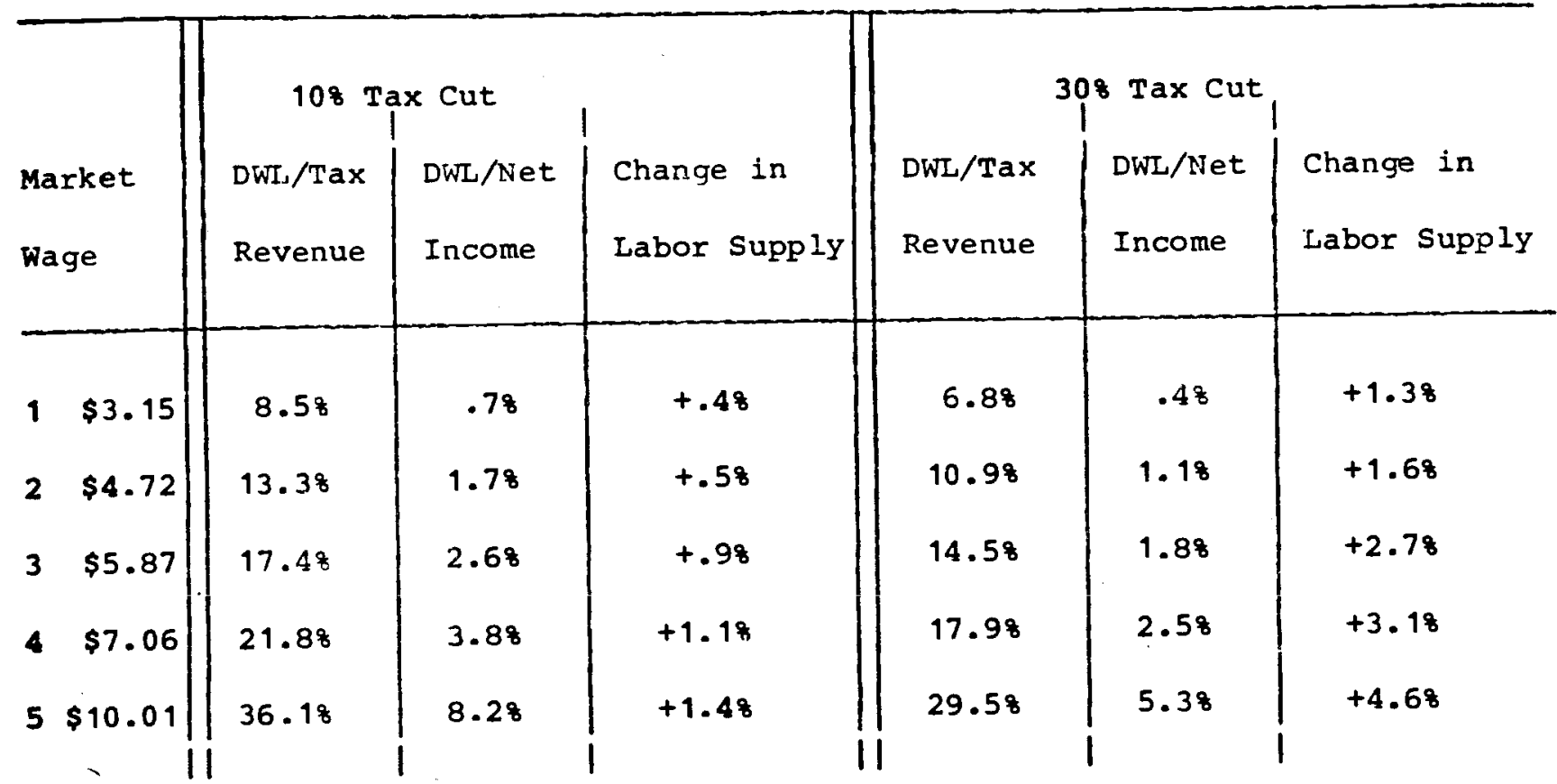

22.5 hours or 1.18 . Tax revenues fall by 7.48 . Even given the fact that our model is partiai equilibrium, rudimentary calculations demonstrate that general equilibrium effects are very unlikely to be large enough to cause tax revenues from decreasing significantly in the short run as our results show. In terms of the welfare cost of the tax we see that the DWL falls significantly. The ratio of mean deadweight loss to tax revenue falls from 22.18 under the current system to 19.08 under the 108 tax cut plan. For the 308 tax cut labor supply Increases by 2.78 while tax revenue falls by 22.68 . Again we see that deadweight loss decreases significantly with the ratio of deadweight loss to cax revenues raised decreasing to $15.4 \%$. In terms of distributional changes the top quintile has the greatest increase in utility as a ratio to net income. Thus as expected, decreasing taxes by a constant percentage reduces deadweight loss but does so in a manner most beneficial to those individuals who face the highest tax rates. Thus Kemp-Roth type tax cuts have large effects both in terms of decreasing deadweight loss and in decreasing government revenue. Without knowledge of marginal government expenditure, it is difficult to evaluate the tradeoff. But we cannot recommend Kemp-Roth on welfare grounds alone given the substantial fall in government revenue. 
Table 3.4 Overall Remp-Roth Tax Cut for Wives

\begin{tabular}{|c|c|c|c|}
\hline & Change in & & Change in \\
\hline Cut & Tax Revenue & Change in DWL & Supply (Hours) \\
\hline
\end{tabular}

1. $10 \%$

$-3.87$

$-10.6 \%$

$+50.2$

2. $30 \%$

$-16.2 \%$

$-17.4 \%$

$+117.0$

For wives we do not present detailed quintile results because the overall pattern is similar to husbands. The mean results are given in Table 3.4 . Overall, we see that the labor supply response to a $t a x$ cut is greater for wives than for husbands. We expect this since the wage elasticity is about twice the income elasticity so we should have a net increase in labor supply. Furthermore the difference in the elasticities is about four times that of husbands, and we do observe a significantly larger response. For the $10 \%$ tax cut case labor supply increases by $4.1 \%$ and tax revenues fall by $3.8 \%$. For the $30 \%$ tax cut case labor supply increases by $9.4 \%$ and tax revenues fall by $16.2 \%$.

Our overall evaluation of the Kemp-Roth tax proposals is that while tax revenues will decrease by significantly less than the $t a x$ cut, overall government revenue from the income and payroll tax will decline. An argument might be made that general equilibrium results may be large enough to reverse this conclusion, but

I doubt that it is a valid argument, especially in the short run. Thus, unless a strong argument $c$ an be made for reducing government expenditures with little welfare loss from the recipients, the Reiap-Roth tax cut proposals cannot be supported on the basis of our results. They certainly do not have the 'free lunch' properties claimed by some of their supporters. 
${ }^{1}$ Sample selection criceria and budget set assumptions are discussed in Hausman (1979). We note that farmers, the self-employed, and severely disabled individuals are excluded from the sample. Potential problems of $t a x$ evasion and $t a x$ avoidence should be decreased by our sample selection procedures. Also, for families with incomes which place them abuve the range of the standard deduction, we used data from the Statistic of Income which should capture a large proportion of tax avoidance procedures. But data problems will nevertheless remain. It certainly seems preferable, however, to account for taxes rather, than to ignore them as is the typical tradition in the labor supply literature, e.g. Smith (1980), in which only one of seven papers recognizes the existence of income taxation.

${ }^{1}$ I disagree with my discussant's remarks about his evidence on the piling up of labor supply at kink points for two reasons. First, the presence of $n$. reduces to zero the probability that anyone is observed at a kink point. We would still observe a dispersion of individuals over the budget set. Second, since the kink points differ for each individual, I do not see how a casual look at the data gives us more evidence. Lastly, he is incorrect in his claim that the ecunometric procedures depend critically on exact knowledge of the location of the kink points.

2 This specification of different tastes for leisure is perhaps the most controversial part of the model since it represents the most marked departure from usual labor supply models where cuefficients are assumed identical across individuals. There all population heterogeneity arises through the additive disturbance term $n_{j}$, e.g. the labor supply models contained in Smith (1980). A further discussion is contained in Hausman (1979). To test for robustness of the specification in Hausman (1979a) I tried different functional forms for the probability distribution. Also, Burtless-Hausman (1978) and Hausman (1979) used instrumental variable techniques which do not depend on normality assumptions. Nor do they depend on the nurmal good assumption for leisure. The results were quite similar to the full maximum likelihood model estimates. I disagree with my discussant's remarks on the robustness of the procedure. My investigations lead me to believe that the procedures I use are considerably more robust than the reservation wage model of labor supply with its unsupported proportionality assumpicion. For instance, in his latest estimates which ignore the existence of taxes, Heckman (1980, p.229), my discussant's estimate of the uncompensated labor supply elasticity for wives changes from 2.1 to 4.8 with only a ininor change in econometric specification. Both estimates are quite high with the latter estimate absurdly so. My estimates are considerably more robust to econometric specification as the labor supply elasticities for the three different budget sets of Table 1.2 indicates.

${ }^{3}$ Other definitions are discussed in Auerbach-Rosen (1980). 
4The women's sample might be becter than the men's sample for cesting this option because the sensicivity around zero hours for a man is probably quite small. Thus biases are not apt to be important for men. However, subsequent simulations have indicated that while the bias is slightly larger for women, it is still probably small snough to be ignored.

${ }^{5}$ Merhod (4) may also be satisfactory for a first approximation.

${ }^{6}$ While relative computer costs are difficult to compare, a simultaion on the full sample of 1000 families on the MIT computer costs around $\$ 60$.

7 When we refer to the current tax system, we are actually using the 1975 data which the model was estimated with. However, except for the rise in social security contribution, the taxation of labor income has not changed significantly since 1975 . 
REFERENCES

Atkinson, A. and J. Stiglitz, "The Design of Tax Structure: Direct versus Indirect Taxation", Journal of Public Economics, 6.

Auerbach, A. and H. Rosen (1980), "Will the Real Excess Burden Stand Up?" mimeo.

Burtless, G. and J. Hausman (1978), "The Effect of Taxation on Labor Supply: The Gary NIT Experiment", Journal of Political Economy, 86.

Diamond, P. and D. McFadden(1974), "Some Uses of the Expenditure Function in Public Finance", Journal of Pub1ic Economics, 3.

Hausman, J. (1979), "The Effect of Taxes on Labor Supply", paper presented at Brookings Conference on Taxation. Forthcoming in $\mathrm{H}$. Aaron and $\mathrm{J}$. Pechman, The Effect of Taxes on Economic Activity.

Hausman, J. (1979a), "The effect of wages, Taxes, and Fixed Costs on Womens' Labor Force Participation", Journal of Public Economics, 14, 1980, pp. 161-194.

Hausman, J. (1979b), "The Econometrics of Labor Supply on Convex Budget Sets", Economic Letters, 3 .

Hausman, J. (1979c), "Exact Consumers' Surplus and Deadweight Loss", forthcoming in American Economic Review.

Heckman, J. (1980), "Sample Bias as a Specification Error," in J.P. Smith (1980).

Smith, J.P. (editor), (1980) Female Labor Supply, Princeton, N.J. 